\title{
Bounded topologies on endomorphism rings
}

\author{
HOREA F. ABRUDAN
}

\section{ABSTRACT.}

We prove in this note that the ring of endomorphisms of an infinite bounded Abelian group admits a nondiscrete right bounded ring topology. We give an example of an Abelian group whose ring of endomorphisms admits both nondiscrete left and right bounded topologies but does not admit a nondiscrete bounded ring topology.

Technical College "Mihai Viteazul"

POIENIŢEI 25, 410191, ORADEA, ROMANiA

E-mail address: abrudan.horea@gmail.com 